\title{
Growth and Characterization of a New Organic Non-Linear Optical (NLO) Material: L-Histidinium Trifluoroacetate
}

\author{
S.A. Martin Britto Dhas ${ }^{1}$, J. Suresh ${ }^{2}$, G. Bhagavannarayana ${ }^{3}$ and S. Natarajan*,1 \\ ${ }^{1}$ Department of Physics, Madurai Kamaraj University, Madurai-625021, India \\ ${ }^{2}$ Department of Physics, The Madura College, Madurai-625011, India \\ ${ }^{3}$ Material Characterization Division, National Physical Laboratory, New Delhi - 110012, India
}

\begin{abstract}
A new organic nonlinear optical (NLO) material L-Histidinium trifluoroacetate was crystallized using LHistidine and trifluoroacetic acid in 1:1 stoichiometric ratio in water-ethanol medium. X-ray diffraction analysis of the single crystals showed that they belong to triclinic system, space group P1, with two molecules per unit cell. The lattice parameters are $\mathrm{a}=5.1673(2) \AA, \mathrm{b}=8.8393(3) \AA, \mathrm{c}=12.4837(6) \AA, \alpha=96.190(3)^{\circ}, \beta=100.020(3)^{\circ}$ and $\gamma=102.010$ $(3)^{\circ}$. The molecules are held together by a three-dimensional network of hydrogen bonds. The crystalline perfection was studied by high resolution X-ray diffraction. The second harmonic generation (SHG) efficiency was measured by Kurtz and Perry method. The FTIR, UV-Vis-NIR spectra and TGA/DTA were recorded and studied. Vickers microhardness measurement was also carried out.
\end{abstract}

\section{INTRODUCTION}

A strong need continues to exist for materials with lower cost, more efficiency and higher laser damage threshold for optical parametric amplifier operation and second-harmonic generation (SHG) throughout the blue-near UV spectral region. Research to obtain very efficient and highly transparent (UV to IR wavelength) NLO crystals is a challenge to physicists, chemists, and material scientists. The performance of optical signal processing devices is linked to the discovery of such new materials. Among NLO materials, organic materials are of special interest because the nonlinear optical response in this broad class of materials is microscopic in origin, offering an opportunity to use theoretical modeling coupled with synthetic flexibility to design and produce novel materials $[1,2]$. Also, one of the advantages in working with organic materials is that they allow one to fine-tune the chemical structures and properties for the desired nonlinear optical properties [3]. In addition, they have large structural diversity. The properties of organic compounds can be refined using molecular engineering and chemical synthesis [4].

Hence, there is a need to synthesize organic NLO materials and study their structural, physical, thermal and optical properties. Our laboratory has launched a programme of finding new NLO materials involving amino acids. LAlaninium maleate [5], L-Prolinium tartrate [6], glycine nitrate [7], L-Cysteine tartrate and L-Histidine nitrate [8] are some of the materials reported recently from our laboratory. Here we report another new material, viz., L-Histidinium trifluoroacetate (LHTFA). Crystal growth, single crystal Xray diffraction, second harmonic generation efficiency, Fou-

*Address correspondence to this author at the Department of Physics, Madurai Kamaraj University, Madurai-625021, India; Tel: 91-04522458471- 352 (extn); Fax: 91-452-2459181;

E-mail: s_natarajan50@yahoo.com rier transform infrared (FTIR) spectra and UV-Vis-NIR spectra and Vickers microhardness measurement are discussed.

\section{EXPERIMENTAL}

\section{Crystal Growth}

L-Histidine and trifluoroacetic acid (E. Merck Ltd., India) were mixed in the stoicheometric ratio of 1:1 in waterethanol mixture. The filtered solution was transferred into a crystallizer and allowed to evaporate slowly under room temperature. Small transparent, rectangular-shaped crystals were obtained in a period of about seven days (Fig. 1).

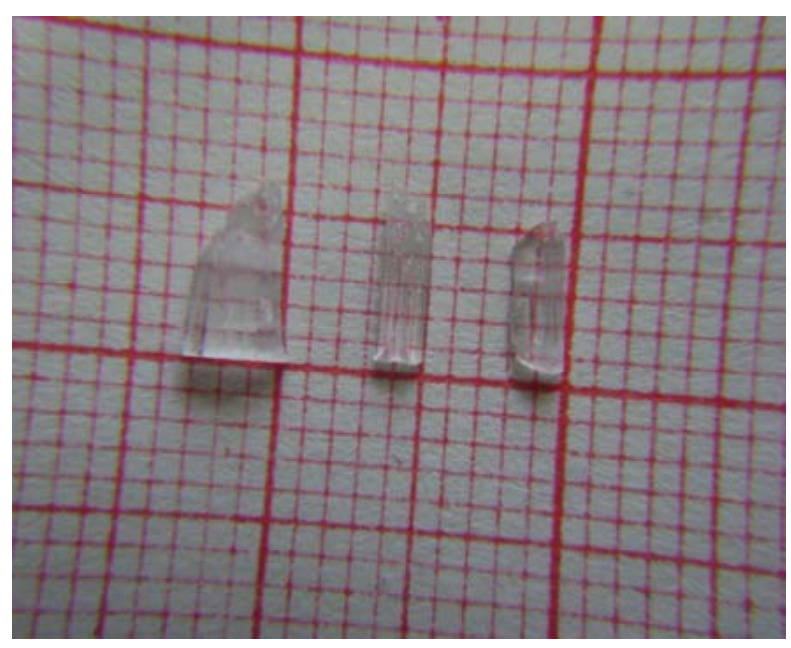

Fig. (1). L-Histidinium trifluoroacetate crystals.

\section{Characterization}

Nonius CAD-4/MACH 3 diffractometer with MoKa $(0.71073 \AA)$ radiation was used to obtain the accurate cell 
parameters of the grown crystals at room temperature, by the least-squares refinement of the setting angles of 25 reflections. To reveal the crystalline perfection of the grown crystals, a 3-crystal X-ray diffractometer developed at the National Physical Laboratory (NPL), New Delhi [9] was used to record the high-resolution diffraction curve (DC) for (003) diffracting plane in symmetrical Bragg geometry. Before recording the diffraction curve, to remove the noncrystallized solute atoms remaining on the surface of the crystal and also to ensure the surface planarity, the specimen was first lapped and chemically etched in a non preferential etchant of water and acetone mixture in 1:2 volume ratio. The nonlinear optical conversion efficiencies were tested using a modified setup of Kurtz and Perry [10]. A Q-switched $\mathrm{Nd}$ :YAG laser beam of wavelength $1064 \mathrm{~nm}$ was used with an input power of $2.0 \mathrm{~mJ}$ and pulse width of $10 \mathrm{~ns}$, the repetition rate being $10 \mathrm{~Hz}$. The crystals were ground to a uniform particle size of about $125-150 \mu \mathrm{m}$ and then packed in a capillary of uniform bore and exposed to laser radiations. The second harmonic signal generated in the crystalline sample was confirmed from the emission of green radiation $(\lambda=532 \mathrm{~nm})$ from the crystal. The intensity of the green light was measured using a photomultiplier tube. The FTIR spectra of LHTFA was recorded in the $\mathrm{KBr}$ phase in the frequency region of $400-3500 \mathrm{~cm}^{-1}$ using Jasco Spectrometer (FTIR, model 410) under a resolution of $4 \mathrm{~cm}^{-1}$ and with a scanning speed of $2 \mathrm{~mm} / \mathrm{sec}$. The transmission spectra for the specimens were recorded using a Varian Cary 5E UVVis - NIR spectrophotometer in the region $200-1200 \mathrm{~nm}$. To find the thermal stability and the thermal decomposition of the grown crystals, simultaneous thermogravimetric analysis (TGA) and differential thermal analysis (DTA) were carried out, using a NETZSCH-Gerätebau STA 409 PC thermal analyzer. A powder sample was used for the analysis in the temperature range of $26{ }^{\circ} \mathrm{C}$ to $800{ }^{\circ} \mathrm{C}$ with a heating rate of $10^{\circ} \mathrm{C} / \mathrm{min}$. The crucible used was of alumina $\left(\mathrm{Al}_{2} \mathrm{O}_{3}\right)$, which served as a reference for the sample. The microhardness of the grown crystals was measured using a Shimadzu Microhardness Tester (Model No HMV2T) with diamond indenter. The well-polished crystal was mounted on the platform of the microhardness tester and loads of different magnitudes $(10,25 \mathrm{gm})$ were applied over a fixed interval of time. The indentation time was fixed as $15 \mathrm{~s}$.

\section{Single Crystal X-Ray Diffraction Studies}

The grown crystals were subjected to X-ray diffraction studies for elucidating the structure at room temperature using Nonius CAD-4/MACH 3 Diffractometer, with $\mathrm{MoK \alpha}$ radiation $(\lambda=0.71073 \AA)$. The accurate cell parameters were obtained from the least-squares refinement of the setting angles of 25 reflections. The crystallographic data are given in Table 1. The molecular structure of LHTFA is shown in Fig. (2). The structural features are discussed in another section.

\section{High Resolution X-Ray Diffraction Studies}

Fig. (3) shows the high-resolution diffraction curve (DC) recorded for a typical LHTFA single crystal grown by slow evaporation solution growth technique (SEST) using (003) diffracting planes in symmetrical Bragg geometry by employing the multicrystal X-ray diffractometer with $M o K \alpha_{1}$ radiation. As seen in the figure, the DC contains a single
Table 1. Crystallographic Data of LHTFA

\begin{tabular}{|l|l|}
\hline Chemical formula & $\left(\mathrm{C}_{6} \mathrm{H}_{10} \mathrm{~N}_{3} \mathrm{O}_{2}\right)^{+} .\left(\mathrm{C}_{2} \mathrm{~F}_{3} \mathrm{O}_{2}\right)^{-}$ \\
\hline Formula weight & 269.19 \\
\hline Temperature & $293(2) \mathrm{K}$ \\
\hline Wavelength & $0.71073 \AA$ \\
\hline Crystal system, space group & Triclinic, $\mathrm{P} 1$ \\
\hline Unit cell dimensions & $\mathrm{a}=5.1673(2) \AA$ \\
\hline & $\mathrm{b}=8.8393(3) \AA$ \\
\hline Programs used: & $\mathrm{c}=12.4837(6) \AA$ \\
\hline Measurement & $\alpha=96.190(3)^{\circ}$ \\
\hline Structure determination & $\beta=100.020(3)^{\circ}$ \\
\hline Refinement & $\gamma=102.010(3)^{\circ}$. \\
\hline Structure drawing & $543.03(4) \AA^{3}$ \\
\hline Folume & $2,1.646$ gm/cc \\
\hline Z, Calculated density & Full-matrix least-squares \\
\hline on F $\mathrm{F}^{2}$
\end{tabular}

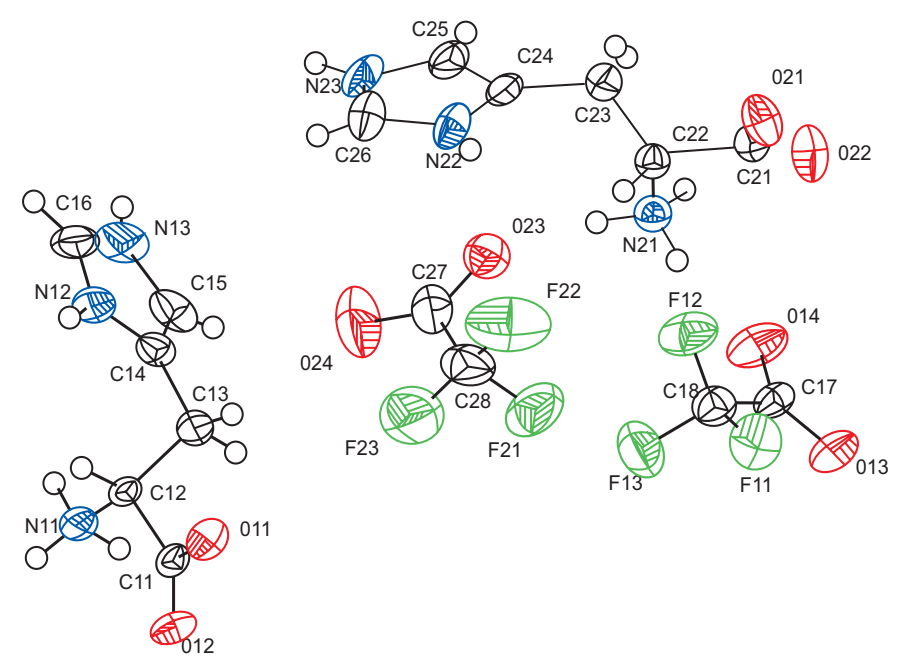

Fig. (2). The molecular structure and numbering of atoms in LHTFA.

peak and shows that this specimen is free from structural grain boundaries. However, the FWHM (full width at half 
maximum) of this curve which is 44 arc secs is somewhat more than that expected from the plane wave theory of dynamical X-ray diffraction [13] for a perfect crystal [1.0 arc sec]. Such broadening is a direct measure of the crystalline defects [14]. It is interesting to see the asymmetry of the DC with respect to the peak position (denoted by the dotted line). For a particular angular deviation $(\Delta \theta)$ of glancing angle with respect to the peak position, the scattered intensity is more in the negative direction in comparison to that of the positive direction. This feature clearly indicates that the crystal contains predominantly vacancy type of defects than that of interstitial defects. This can be well understood by the fact that due to vacancy defects which might be aroused due to fast growth, the lattice around these defects undergo tensile stress and the lattice parameter $d$ (interplanar spacing) increases and leads to give more scattered (also known as diffuse $\mathrm{X}$ ray scattering) intensity at slightly lower Bragg angles $\left(\theta_{\mathrm{B}}\right)$ as $\mathrm{d}$ and $\sin \theta_{\mathrm{B}}$ are inversely proportional to each other in the Bragg equation $\left(2 \mathrm{~d} \sin \theta_{\mathrm{B}}=\mathrm{n} \lambda ; \mathrm{n}\right.$ and $\lambda$ being the order of reflection and wavelength respectively which are fixed). However, these point defects with much lesser density as in the present case (if the concentration is high, the FWHM would be much higher and often lead to structural grain boundaries) hardly give any effect in the performance of the devices based on such crystals.

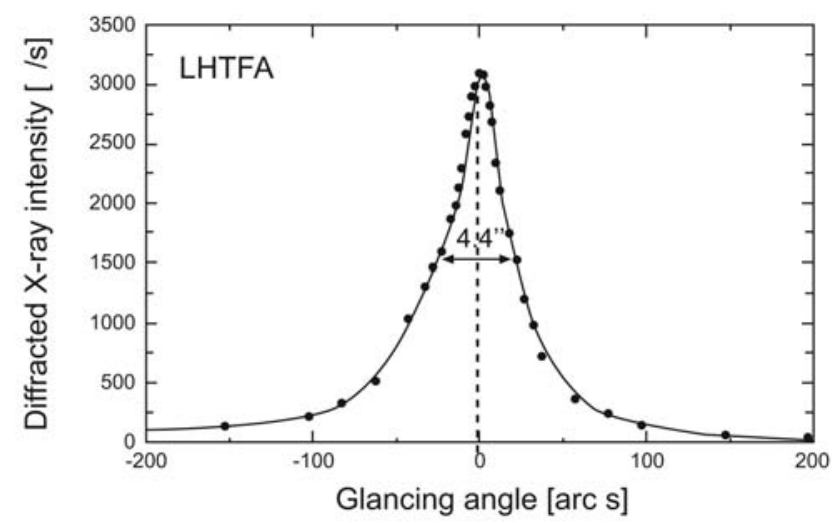

Fig. (3). Diffraction curve recorded for LHTFA single crystal for (003) diffracting planes by employing the multicrystal X-ray diffractometer with $\mathrm{MoK} \alpha_{1}$ radiation.

\section{SECOND HARMONIC GENERATION}

Since LHTFA crystallized in a non-centrosymmetric space group, it was thought that there is a possibility for second harmonic generation. A preliminary study of the powder SHG conversion efficiency was also carried out with a $\mathrm{Nd}$ : YAG laser beam of wavelength $1064 \mathrm{~nm}$. The SHG efficiency was found to be about 1.2 times that of the standard KDP crystal.

The level of SHG response of a given material is inherently dependent on the molecular and supramolecular nature of the compound. The nature of the crystal packing, local crystal-field effects and intermolecular interactions highly influence the SHG effect [15]. On a molecular scale, the extent of charge transfer (CT) across the NLO chromophore determines the level of SHG output, the greater the CT, the larger the SHG output. The presence of strong intermolecu- lar interactions, such as hydrogen bonds, can extend this level of CT into the supramolecular realm, owing to their electrostatic and directed nature, thereby enhancing the SHG response [16, 17]. In LHTFA, the three-dimensional network of N-H...O bonds link the cations and trifluoroacetate anions, stabilizing the crystal packing. The histidinium trifluroacetate molecules are arranged as an array along the a-axis (Fig. 4). The inter-planar distance between the two five membered rings is $3.336 \AA$ which falls in the category of $\pi-\pi$ stacking. Such parallel and close stacking is very favorable for the promotion of CT through the lattice. Thus, the large number of hydrogen bonds and the close stacking of histidine cation enhance the SHG activity of this material [18].

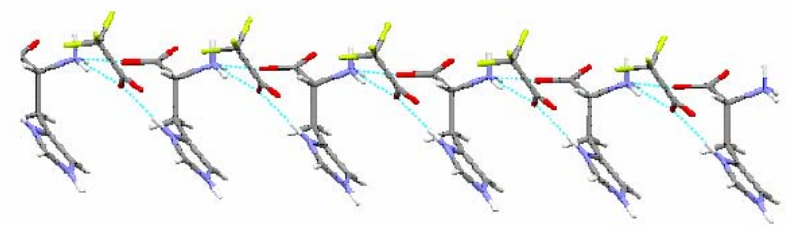

Fig. (4). A view of parallel stacking of histidinium trifluroacetate molecules and the $\mathrm{N}-\mathrm{H} \cdots \mathrm{O}$ hydrogen bonds (dashed lines) running along the a-axis of the unit cell. (red - oxygen, blue - nitrogen, yellow - fluorine, black - carbon).

\section{FTIR AND UV-VIS-NIR STUDIES}

The recorded FTIR spectra (Fig. 5) were compared with the standard spectra of the functional groups [19]. The tentative assignments are given in Table 2 .

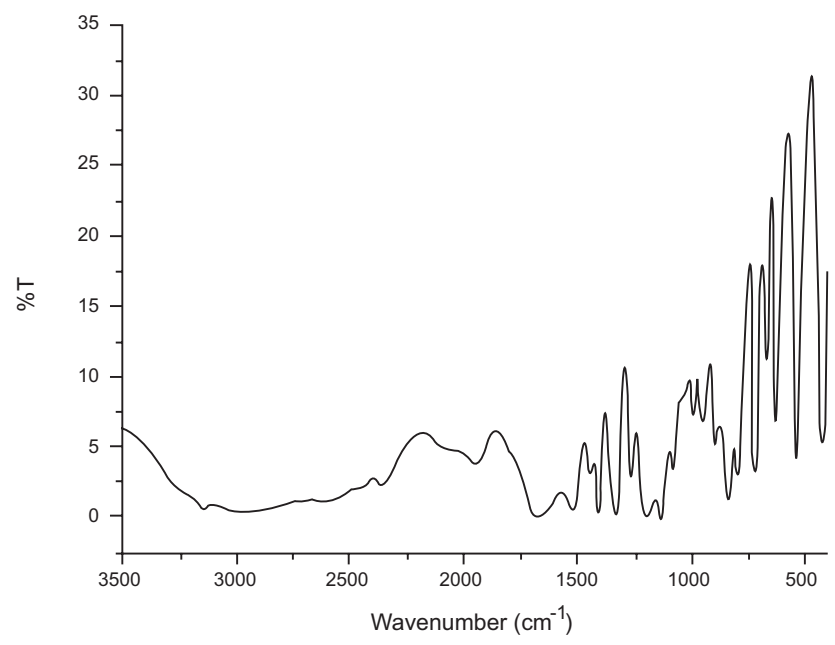

Fig. (5). FTIR spectra of LHTFA.

The UV-Vis-NIR transmission spectrum of LHTFA crystal was recorded in the range: $200-1200 \mathrm{~nm}$ covering the entire near-ultraviolet, visible and NIR regions and is shown in Fig. (6). From the UV-Vis-NIR spectrum, it is seen that the UV transparency cutoff occurs at $220 \mathrm{~nm}$ and the sharp peak at $230 \mathrm{~nm}$ is due to the $\pi-\pi^{*}$ electron transition. There is no remarkable absorption in the entire region of the spectra. This is good enough for the production of shorter wavelength violet - green radiation from the infrared laser sources. One typical example is the optical up-conversion of 
the fundamental Nd:YAG laser $(1064 \mathrm{~nm})$ radiation into the green radiation (second harmonic, $532 \mathrm{~nm}$ ) and violet radiation (third harmonic, $354.6 \mathrm{~nm}$ ).

Table 2. FTIR Spectral Data of LHTFA

\begin{tabular}{|c|c|}
\hline Wave Number $\left(\mathrm{cm}^{-1}\right)$ & Tentative Assignments \\
\hline 3144 & $\mathrm{NH}_{3}{ }^{+}$stretching \\
\hline 2366 & $\mathrm{C}-\mathrm{H}$ combinational overtone \\
\hline 1688 & $\mathrm{C}=\mathrm{O}$ stretching \\
\hline 1524 & $\mathrm{~N}=\mathrm{C}-\mathrm{N}$ stretching \\
\hline 1445 & C-O stretching \\
\hline 1406 & $\mathrm{O}-\mathrm{H}$ deformation \\
\hline 1334 & C-F stretching \\
\hline 1265 & C-F stretching \\
\hline 1201 & C-F stretching \\
\hline 1138 & C-F stretching \\
\hline 1080 & C-N stretching \\
\hline 835 & $\mathrm{C}-\mathrm{H}$ out of plane deformation \\
\hline 797 & $\mathrm{NH}_{3}{ }^{+}$rocking \\
\hline 719 & $\mathrm{~N}-\mathrm{H}$ bending \\
\hline 629 & C-C deformation \\
\hline 542 & $\mathrm{C}-\mathrm{C}=\mathrm{O}$ in-plane vibration \\
\hline
\end{tabular}

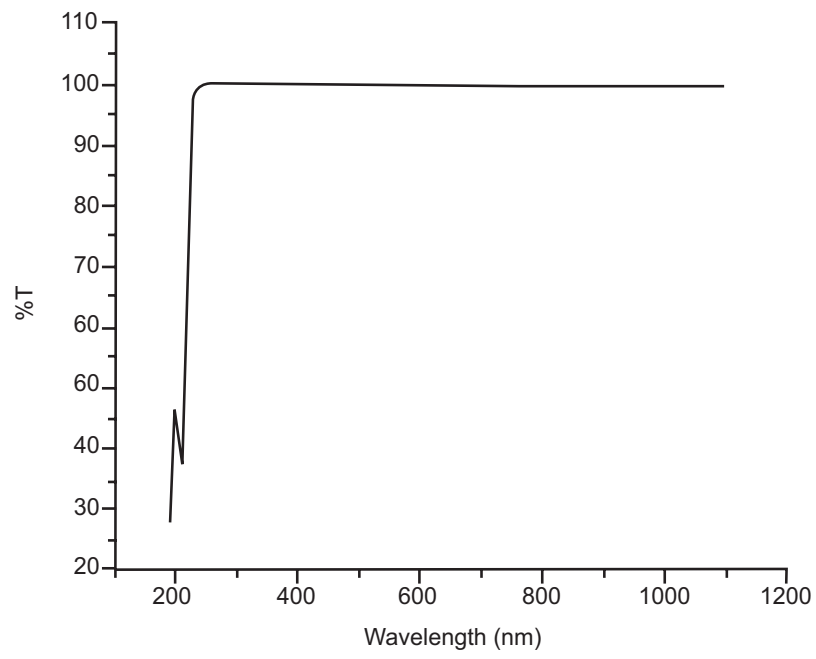

Fig. (6). Transmission spectrum of LHTFA.

\section{TGA/DTA STUDIES}

Fig. (7) shows the TGA/DTA trace of LHTFA. The endothermic peak at $216{ }^{\circ} \mathrm{C}$ is due to the melting point. The sharp endothermic peak shows the good crystalline perfection (quality) of the sample. There are no endothermic or exothermic peaks observed before $216^{\circ} \mathrm{C}$. It shows that this crystal is stable up to the melting point without any phase transition. Immediately, it starts to decompose. In the first stage, trifluroacetic acid got evaporated completely and followed by the liberation of $\mathrm{CO}_{2}$ from the histidine leading to a major mass reduction of $58.6 \%$. After that, the remaining molecules decomposed and get liberated gradually.

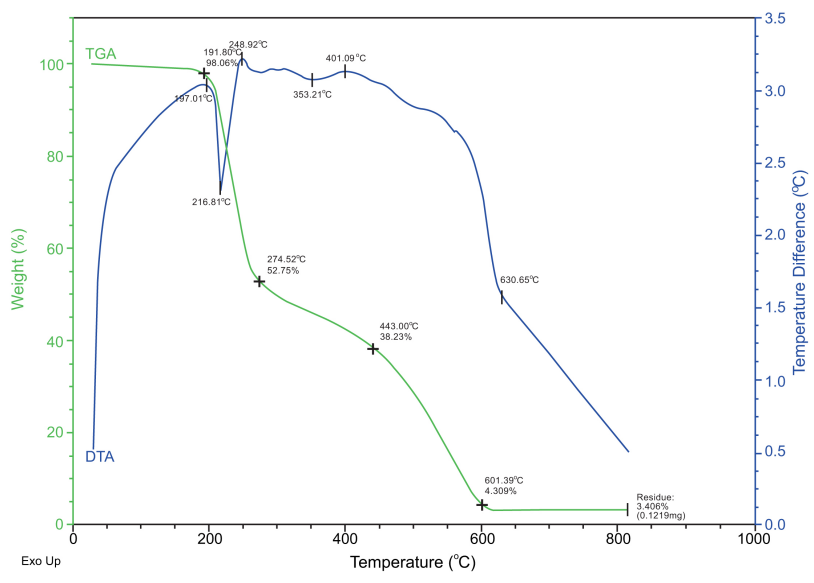

Fig. (7). TGA/DTA of LHTFA.

\section{MICROHARDNESS STUDIES}

The well polished crystal was mounted on the platform of the Vickers microhardness tester and loads of different magnitudes $(10,25 \mathrm{gm})$ were applied over a fixed interval of time (for the plane 003). The indentation time was fixed as $15 \mathrm{~s}$. The hardness was calculated as $54.9 \mathrm{Kg} \mathrm{mm}^{-1}$. When the load was increased to values above $25 \mathrm{~g}$, cracks developed on the smooth surface of the crystal due to the release of internal stress generated locally by indentation.

\section{CONCLUSIONS}

A new organic NLO material was successfully grown using slow evaporation method at room temperature and its structure was elucidated using single crystal X-ray diffraction technique. The high resolution X-ray diffraction studies showed that the crystal contains predominantly vacancy type of defects than that of interstitial defects. Assignments were made for the functional groups in the compound, using the FTIR spectra. UV-Vis-NIR study showed that the crystal is transparent for the fundamental, second and third harmonic generation of Nd: YAG $(\lambda=1064 \mathrm{~nm})$ laser. The TGA/DTA studies showed that this crystal is stable upto $216^{\circ} \mathrm{C}$ without any phase transition. The SHG efficiency was measured using Kurtz and Perry method and is found to be about 1.2 times that of the standard KDP crystal. These results show that LHTFA is a NLO material with possible applications for frequency conversion.

\section{ACKNOWLEDGEMENTS}

The authors thank the DST-FIST Programme and SAMB thanks the Madurai Kamaraj University, Madurai for providing a Research Fellowship.

\section{REFERENCES}

[1] Prasad PN, Williams DJ. Introduction to Nonlinear Optical Effects in Organic Molecules and Polymers. Wiley, New York, 1991.

[2] Chemla DS, Zyss J. (Eds). Nonlinear Optical Properties of Organic Molecules and Crystals; Academic Press: New York, 1987. 
[3] Datta A and Pati SK. Dipole orientation effects on nonlinear optical properties of organic molecular aggregates J Chem Phys 2003; 118: 8420-7.

[4] De Matos G, Venkataraman V, Nogueria E, et al. Synthesis, Crystal growth and characterisation of a new nonlinear optical material — urea L-malic acid. Synth Met 2000; 115: 225-8.

[5] Natarajan S, Martin Britto SA and Ramachandran E. Growth, Thermal, Spectroscopic, and Optical Studies of L-Alaninium Maleate, a New Organic Nonlinear Optical Material Cryst. Growth Des 2006; 6: 137-140.

[6] Martin Britto Dhas SA and Natarajan S. Growth and characterization of L-prolinium tartrate - A new organic NLO material S. Cryst Res Technol 2007; 42: 471-6.

[7] Martin Britto Dhas SA and Natarajan S. Growth and characterization of a new organic NLO material: Glycine nitrate. Opt Commun 2007; 278: 434-8.

[8] Martin Britto Dhas SA and Natarajan S. Growth and characterization of two new NLO materials from the amino acid family: LHistidine nitrate and L-Cysteine tartrate monohydrate. Opt Commun 2008; 281: 457-62.

[9] Krishan Lal and Bhagavannarayana G. A high-resolution diffuse X-ray scattering study of defects in dislocation-free silicon crystals grown by the float-zone method and comparison with Czochralskigrown crystals. J Appl Cryst 1989; 22: 209-15.

[10] Kurtz SK and Perry TT. A powder technique for the evaluation of nonlinear optical materials. J Appl Phys 1968; 39: 3798-813.
[11] Enraf-Nonius, CAD-4 EXPRESS Version 5.11.2, Enraf-Nonius, Delft, The Netherlands, 1994.

[12] Sheldrick GM. Phase annealing in SHELX-90: direct methods for larger structures. Acta Cryst 1990; A46: 467-73.

[13] Betterman BW and Cole H. Dynamical Diffraction of X Rays by Perfect Crystals. Rev Mod Phys 1964; 36: 681-717.

[14] Kar S, Ryu H and Bartwal KS. High Resolution XRD Studies on $\mathrm{Mg}, \mathrm{Cr}$ and $\mathrm{Nd}$ Doped $\mathrm{LiNbO}_{3}$ Crystals. Open Crystallogr J 2008; 1: $1-5$.

[15] Cole JM, Goeta AE, Howard JAK and Mclntyre GJ. X-ray and neutron diffraction studies of the non-linear optical compounds MBANP and MBADNP at $20 \mathrm{~K}$ : charge-density and hydrogenbonding analyses. Acta Cryst 2002; B58: 690 -700.

[16] Oudar JL. Optical nonlinearities of conjugated molecules. Stilbene derivatives and highly polar aromatic compounds J Chem Phys 1977; 67: 446-57.

[17] Oudar JL and Zyss. Relations between microscopic and macroscopic lowest-order optical nonlinearities of molecular crystals with one- or two-dimensional units J Phys Rev A 1982; 26: 2028 48.

[18] Cole JM, Howard AKJ and Mclntyre GJ. Influence of hydrogen bonding on the second harmonic generation effect: neutron diffraction study of 4-nitro-4'-methylbenzylidene aniline. Acta Cryst 2001; B57: 410.

[19] Socrates G. Infrared Characteristic Group Frequencies, WileyInterscience: Chichester, 1980.

(C) Dhas et al.; Licensee Bentham Open.

This is an open access article licensed under the terms of the Creative Commons Attribution Non-Commercial License (http://creativecommons.org/licenses/by-nc/3.0/) which permits unrestricted, non-commercial use, distribution and reproduction in any medium, provided the work is properly cited. 